\title{
Total hip and knee joint replacement: perioperative clinical aspects
}

\author{
Artroplastia total de quadril e joelho: aspectos clínicos na fase perioperatória
}

\author{
Luciana Pereira Almeida de Piano ${ }^{1}$, Ricardo Prado Golmia ${ }^{2}$, Morton Scheinberg ${ }^{3}$
}

\begin{abstract}
Objective: To understand the profile of patients undergoing hip and knee replacement during two years, and to compare the data obtained with the literature. Methods: A total of 323 medical records were reviewed to analyze the perioperative data of patients submitted to hip and knee replacement. Results: 0steoarthritis was the main indication for both procedures and male patients were heavier than females $(p<0.05)$. Hypertension was the prevalent disease among patients. Blood loss was more frequent in knee surgery than in the hip. Conclusions: The profile of patients undergoing total arthroplasty improved substantially over the past decade due to shorter hospital stay, lower risk of thromboembolic events and no infection as compared to previous reports.
\end{abstract}

Keywords: Arthroplasty, replacement, knee/epidemiology; Arthroplasty, replacement, hip/epidemiology; Perioperative care

\section{RESUMO}

Objetivo: Conhecer o perfil dos pacientes submetidos à artroplastia de quadril e joelho em um período de dois anos e comparar os dados com relatos da literatura. Métodos: Foram revisados 323 prontuários para analisar os dados perioperatórios de pacientes submetidos à substituição da articulação do joelho e do quadril. Resultados: A osteoartrite foi a principal indicação para ambos os procedimentos, e os homens mostraram-se mais pesados que as mulheres $(p<0,05)$. A hipertensão arterial foi a doença prevalente entre os pacientes. A perda sanguínea foi mais frequente na cirurgia do joelho do que na do quadril. Conclusões: 0 perfil dos pacientes submetidos à artroplastia melhorou substancialmente nos últimos dez anos, associando a diminuição do período de internação com menor risco de eventos tromboembólicos e ausência de infecção, quando comparados com publicações anteriores.

Descritores: Artroplastia do joelho/epidemiologia; Artroplastia de quadril/epidemiologia; Assistência perioperatória

\section{INTRODUCTION}

The use of hip and knee joint replacement has been steadily increasing during the last decade because these are effective procedures that improve the patients' quality of life, their functional capacity and diminish the pain ${ }^{(1-7)}$.

Although joint replacement is a cost-effective treatment both from the clinical and joint perspective, there is a considerable variation on the clinical aspects surrounding the procedure from the perioperative period until the moment of discharge, including variations according to region, sex, race or socioeconomic status, aspects related to the surgical technique itself and the duration of prophylaxis against infections and venous thromboembolism, among others. In addition, with the increase in the prevalence of arthritis, obesity, and old age, a further increase in total knee and joint replacement procedures can been anticipated ${ }^{(5,8,9)}$.

The analysis of the evolution of hip and knee arthroplasties can enlighten information on future developments of the surgery as well as to the population characteristics. The present paper reports the findings observed on the cases submitted to arthroplasties at a specialized institution for the care of bone and joint diseases.

\section{OBJECTIVE}

To understand the profile of patients undergoing hip and knee replacement during two years at a specialized institution for the care of musculoeskeletal diseases, and to compare the data obtained from the literature.

\footnotetext{
Study carried out at Hospital Abreu Sodré da Associação de Assistência à Criança Deficiente - AACD, São Paulo (SP), Brazil.

Biomedical professional; PhD in Cardiology; Clinical Research Coordinator at Hospital Abreu Sodré da Associação de Assistência à Criança Deficiente - AACD, São Paulo (SP), Brazil.

${ }^{2}$ Rheumatologist at Santa Casa de Misericórdia de São Paulo - SCMSP, São Paulo (SP) Brazil; Researcher at the Clinical Research Center of Hospital Abreu Sodré da Associação de Assistência à Criança Deficiente - AACD, São Paulo (SP), Brazil.

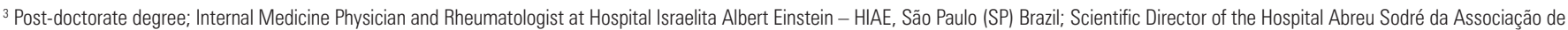
Assistência à Criança Deficiente - AACD, São Paulo (SP), Brazil.

Received on Mar 9, 2010 - Accepted on Jun 9, 2010

Corresponding author: Luciana Pereira Almeida de Piano - Avenida Professor Ascendino Reis, 724 - Vila Clementino - CEP 04027-000 - São Paulo (SP), Brazil - Tel.: (11) 5576-0788 - E-mail: Ipiano@aacd.org.br
} 


\section{METHODS}

A retrospective analysis was performed in medical records of all knee and hip replacements done at the Hospital Abreu Sodré da Associação de Assistência à Criança Deficiente (AACD), during the period of 2008-2009, with approval from the Researcher Ethics Committee - CEP 90/2010. Baseline demographic data including age, sex, diagnosis, associated diseases and etiologic diagnosis were recorded. The clinical data collected after the procedure comprised days of hospitalization, blood loss, infection and thromboembolism, comparison between total knee arthroplasty (TKA) and total hip arthroplasty (THA). Descriptive analyses were performed. Data collection could not be performed in 23 charts during this period.

\section{RESULTS}

A total of 323 medical records were reviewed, 225 (69.7\%) for knee replacement and the remainder for hip procedures. Table 1 summarizes the demographic data per type of procedure. Sex was significantly different in both types of replacement and women were older than man. When comparing weight of patients in both surgeries, men were heavier than women, and the difference was statistically significant $(\mathrm{p}<0.05)$. Table 2 presents the indications for total joint replacement and the type of surgery performed. Osteoarthritis was the main indication for both procedures, followed by a small number of other causes, including inflammatory arthritis.

Table 1. Demographics and type of joint replacement

\begin{tabular}{lcc} 
Characteristics & $\begin{array}{c}\text { Knee arthroplasty } \\
\mathbf{n = 2 2 5}(\mathbf{6 9 . 7 \%})\end{array}$ & $\begin{array}{c}\text { Hip arthroplasty } \\
\mathbf{n = 9 8}(\mathbf{3 0 . 3} \%)\end{array}$ \\
\hline Male n (\%) & $46(20.4)$ & $37(37.8)$ \\
Female n (\%) & $179(79.6)$ & $61(62.2)$ \\
Mean age (years + SD) & $66.7(11.5)$ & $57.5(16.7)$ \\
Male & $64.6(13.5)$ & $54.5(14.8)$ \\
Female & $67.3(10.4)$ & $61.0(17.1)$ \\
Mean weight $(\mathrm{kg}+\mathrm{SD})$ & $77.3(15.5)$ & $77.7(17.4)$ \\
Male & $85.7(17.5)$ & $87.4(13.8)$ \\
Female & $75.1(14.5)$ & $74.0(8.4)$ \\
\hline
\end{tabular}

Table 2. Indications for arthroplasty and type of replacement

\begin{tabular}{lcc}
\hline Diseases/surgery & $\begin{array}{c}\text { Knee arthroplasty } \\
\mathbf{n}(\%)\end{array}$ & $\begin{array}{c}\text { Hip arthroplasty } \\
\mathbf{n}(\%)\end{array}$ \\
\hline Disease & $218(96.9)$ & $91(92.4)$ \\
Osteoarthritis & $2(0.9)$ & $4(4.1)$ \\
Osteonecrosis & $6(2.7)$ & $2(2)$ \\
Inflammatory arthritis & $1(0.4)$ & $4(4.1)$ \\
Hip fracture & $1(0.4)$ & $2(2)$ \\
Failed osteosynthesis & & $47(48)$ \\
Type of replacement & $224(99.55)$ & $50(51)$ \\
Cemented & $1(0.5)$ & \\
Non-cemented & & \\
\hline
\end{tabular}

Table 3 shows the variables related to the procedure itself and comorbidities that could affect the perioperative and immediate postoperative outcomes. Arterial hypertension was the most prevalent medical condition found in patients operated at the institution for both knee and hip surgeries. Blood loss was more prevalent in knee surgery when compared to the procedure of hip replacement. No major differences were observed in other social and morbidity factors, including diabetes, smoking, anemia and complicating factors due to infection. The average length of stay was similar for both procedures. All patients received low-dose low-molecular-weight heparin and no immediate thrombotic events were recorded. Figure 1 shows a preliminary evaluation of this population according to the number of joint replacements.

Table 3. Variables related to the procedure and comorbidities during the perioperative and postoperative periods

\begin{tabular}{lcc}
\hline Data & $\begin{array}{c}\text { Knee } \\
\mathbf{n}(\%)\end{array}$ & $\begin{array}{c}\text { Hip } \\
\mathbf{n}(\%)\end{array}$ \\
\hline Associated disease & & \\
$\quad$ Osteoporosis & $13(5.8)$ & $1(1)$ \\
Diabetes & $11(4.9)$ & $9(9.2)$ \\
$\quad$ Systemic arterial hypertension & $63(28)$ & $45(45.9)$ \\
$\quad$ Cardiac disease & $11(4.9)$ & $9(9.2)$ \\
$\quad$ Smoking & $6(2.7)$ & $13(13.3)$ \\
Complications & & \\
Infection & $5(2.2)$ & $1(1.0)$ \\
$\quad$ Revision & $10(4.4)$ & $7(7.1)$ \\
$\quad$ Fever & $2(0.9)$ & 0 \\
Hematology/Thrombotic profile & & $10.4(1.5)$ \\
Hb (SD) & $11.1(1.5)$ & $30.4(4.6)$ \\
Ht (SD) & $32.9(4.5)$ & 0 \\
Thrombotic events (\%) & $1(0.4)$ & $356.2(303)$ \\
Blood loss (drainage - ml/24 & $452.6(278.9)$ & $4(4.1)$ \\
hours) (SD) & $15(6.7)$ & $5.5(4)$ \\
Use of corticosteroids & $5.3(2.9)$ & \\
Length of stay (days) (SD) & &
\end{tabular}

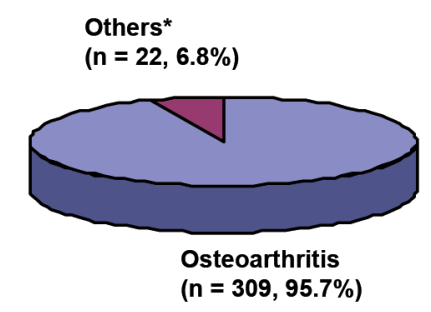

Total number of patients is greater than the total sample of the study, since some cases presented more than one associated disease.

${ }^{*}$ Osteonecrosis, inflammatory arthritis, hip fracture, failed osteosynthesis.

Figure 1. Joint diseases before joint replacement 


\section{DISCUSSION}

There are few studies evaluating exclusively the perioperative period of TKA and THA. The findings of the present study indicated some points of interest when compared to other reports from the literature.

Knee and hip replacements were systematically more frequent in women than in men at this hospital. The female/male ratio for both procedures was similar to that reported by Culliford et al. ${ }^{(10)}$, who analyzed temporal trends in joint replacement in the United Kingdom, from 1991 to 2006. However, in their investigation, the rate of TKA was considerably lower than that of the hip, unlike the present study ${ }^{(10)}$. These differences may be due to sampling variations. Another hypothesis is that the present patient population comes through health maintenance organizations, while in the UK other regulations apply to patients from the National Health Service referred to joint replacements.

Although men were heavier than women, they had less joint replacements, and the diagnosis of osteoarthritis was more prevalent in females than in the general population. The age of the studied population was similar to previous reports. As mentioned above, the prevalence of THA surpassing TKA was not in accordance with other publications ${ }^{(10,11)}$. In the present study, knee replacement was twice more frequent than hip procedures in a given period.

Patients undergoing total joint replacement run a high risk of developing venous thromboembolism; however, when prophylaxis is appropriate, like in this study, the risk drops considerably. At Hospital Abreu Sodré - AACD, the frequency of thromboembolic events during the period evaluated was very low (under $1 \%$ ). In various studies, venous thrombosis was reported in approximately $19 \%$ of cases before prophylaxis ${ }^{(12,13)}$. In the present series, only one patient had venous thromboembolism during hospitalization. There are reports that patients submitted to TKA are more susceptible to venous thromboembolism than those undergoing THA. This difference could not be evaluated in the present investigation, for only one patient presented this complication. White et al. ${ }^{(14)}$ suggested extended prophylaxis after knee surgeries. In the present study, there were no differences in the immediate postoperative period for both joints as to frequency of deep venous thrombosis. The majority of cases occurred after hospital discharge, and this data would not have been collected, although patients were on thrombotic prophylaxis up to six days after surgery and were on low-dose lowmolecular-weight heparin while at hospital under medical supervision. A prospective study is suggested to evaluate thromboembolic events in longer postoperative periods, and to assess other parameters.
Hospital Abreu Sodré - AACD is a reference center for bone and joint diseases in a non-academic setting. A previous comparison between academic and nonacademic institutions failed to show differences in length of hospital stay and in perioperative outcomes for knee and hip arthroplasties ${ }^{(9)}$. However, the length of stay of this study was almost two days shorter than that reported by Fortin et al. ${ }^{(1)}$. When comparing the current series with an academic institution, the health status was similar in both procedures, and apparently did not influence on the immediate outcome. In contrast to a previous publication by March et al. ${ }^{(8)}$, inflammatory and non-inflammatory arthritis could not be evaluated since the number of rheumatoid arthritis patients was significantly small in the present study. The current trend is a considerable drop in the number of joint replacements after the introduction of biologic therapy, and only $2 \%$ of cases were due to inflammatory arthritis ${ }^{(15,16)}$. A preliminary evaluation in the studied population seemed to confirm such observations.

Wound disturbances were not found in the patients of both procedures. Naylor et al. reported a high frequency of these events ${ }^{(17)}$ In the present study, patients received prophylaxis with antibiotics, which may explain some of the differences in relation to other reports.

Some demographic aspects were similar to those described by Ghandi and $\mathrm{Tso}^{(9)}$. However, the etiology of diseases in this study was quite different. Costs were not analyzed and should be included in further studies; nonetheless, there are reports that nonteaching hospitals, such as the present setting, tend to have reduced cost in resource consumption for joint replacement surgery. The population of the present study, as mentioned above, comprised mainly osteoarthritic patients and recent studies suggested similar costs for procedures related to osteoarthritis and rheumatoid arthritis ${ }^{(8,18,19)}$.

It was reported that the perioperative knee replacement outcomes were worst when compared to hip replacement ${ }^{(18)}$. These data could not be confirmed in this series, since postoperative results in both procedures (THA and TKA) were similar.

Although some reports are from the past decade, improvement in hospital care may account for the difference in the present results as compared to the literature ${ }^{(17,19-21)}$. Finally, the results may also depend on other factors that were not clearly described in previous publications such as individual characteristics and success of the operation itself( ${ }^{(22,23)}$.

\section{CONCLUSIONS}

This study showed that, in the perioperative period, the profile of patients undergoing total joint replacement 
has improved substantially during the last ten years, when compared to previous reports, in terms of shorter hospital stay, lower risk of thromboembolic events and absence of immediate infection.

\section{REFERENCES}

1. Fortin PR, Clarke $A E$, Joseph $L$, Liang $M H$, Tanzer $M$, Ferland $D$, et al. Outcomes of total hip and knee replacement: preoperative functional status predicts outcomes at six months after surgery. Arthritis Rheum. 1999;42(8):1722-8.

2. Barbieri A, Vanhaecht $K$, Van Herck P, Sermeus W, Faggiano F, Marchisio S, et al. Effects of clinical pathways in the joint replacement: a meta-analysis. BMC Med. 2009;7:32

3. Gandhi R, Davey JR, Mahomed NN. Predicting patient dissatisfaction following joint replacement surgery. J Rheumatol. 2008;35(12):2415-8.

4. Gandhi R, Dhotar H, Razak F, Tso P, Davey JR, Mahomed NN. Predicting the longer term outcomes of total knee arthroplasty. Knee. 2010;17(1):15-8.

5. Almeida RF, de Queiroz AA, Belloti JC, de Castro Filho JM, Cohen M, Navarro RD. Approach towards total knee arthroplasty in Brazil: cross-sectional study. Sao Paulo Med J. 2009;127(4):190-7.

6. da Silva E, Doran MF, Crowson CS, O'Fallon WM, Matteson EL. Declining use of orthopedic surgery in patients with rheumatoid arthritis? Results of a long-term, population-based assessment. Arthritis Rheum. 2003;49(2):216-20.

7. Ward MM. Decreases in rates of hospitalizations for manifestations of severe rheumatoid arthritis, 1983-2001. Arthritis Rheum. 2004;50(4):1122-31.

8. March LM, Barcenilla AL, Cross MJ, Lapsley HM, Parker D, Brooks PM. Costs and outcomes of total hip and knee joint replacement for rheumatoid arthritis. Clin Rheumatol. 2008;27(10):1235-42.

9. Gandhi R, Tso P, Davis A, Mahomed NN. Outcomes of total joint arthroplasty in academic versus community hospitals. Can J Surg. 2009;52(5):413-6.

10. Culliford DJ, Maskell J, Beard DJ, Murray DW, Price AJ, Arden NK. Temporal trends in hip and knee replacement in the United Kingdom: 1991 to 2006. J Bone Joint Surg Br. 2010;92(1):130-5.
11. Quintana JM, Arostegui I, Escobar A, Azkarate J, Goenaga JI, Lafuente I. Prevalence of knee and hip osteoarthritis and the appropriateness of joint replacement in an older population. Arch Intern Med. 2008;168(14):1576-84.

12. Ansari S, Warwick D, Ackroyd CE, Newman JH. Incidence of fatal pulmonary embolism after 1,390 knee arthroplasties without routine prophylactic anticoagulation, except in high-risk cases. J Arthroplasty. 1997;12(6):599-602.

13. Morrey BF, Adams RA, Ilstrup DM, Bryan RS. Complications and mortality associated with bilateral or unilateral total knee arthroplasty. J Bone Joint Surg Am. 1987;69(4):484-8

14. White RH, Romano PS, Zhou H, Rodrigo J, Bargar W. Incidence and time course of thromboembolic outcomes following total hip or knee arthroplasty. Arch Intern Med. 1998;158(14):1525-31.

15. Momohara S, Inoue E, Ikari K, Kawamura K, Tsukahara S, Iwamoto T, et al. Decrease in orthopaedic operations, including total joint replacements, in patients with rheumatoid arthritis between 2001 and 2007: data from Japanese outpatients in a single institute-based large observational cohort (IORRA). Ann Rheum Dis. 2010;69(1):312-3.

16. Kolling C, Herren DB, Simmen BR, Goldhahn J. Changes in surgical intervention patterns in rheumatoid arthritis over 10 years in one centre. Ann Rheum Dis. 2009;68(8):1372-3.

17. Naylor JM, Harmer AR, Heard RC, Harris IA. Patterns of recovery following knee and hip replacement in an Australian cohort. Aust Health Rev. 2009;33(1):124-35.

18. O'Brien S, BennettD, DoranE, Beverland DE. Comparison of hip and knee arthroplasty outcomes at early and intermediate follow-up. Orthopedics. 2009;32(3):168.

19. Sloan FA, Feldman RD, Steinwald AB. Effects of teaching on hospital costs. J Health Econ. 1983;2(1):1-28.

20. Ritter MA, Wing JT, Berend ME, Davis KE, Meding JB. The clinical effect of gender on outcome of total knee arthroplasty. J Arthroplasty. 2008;23(3):331-6.

21. Ritter MA, Albohm MJ, Keating EM, Faris PM, Meding JB. Life expectancy after total hip arthroplasty. J Arthroplasty. 1998;13(8):874-5.

22. Norman-Taylor FH, Palmer CR, Villar RN. Quality-of-life improvement compared after hip and knee replacement. J Bone Joint Surg Br. 1996;78(1):74-7.

23. Bourne RB, Chesworth B, Davis A, Mahomed N, Charron K. Comparing patient outcomes after THA and TKA: is there a difference? Clin Orthop Relat Res. 2010;468(2):542-6. 